\title{
AMMONIUM AND FORMATE IONS IN INTERSTELLAR ICE ANALOGS
}

\author{
Oscar Gálvez, Belén Maté, Victor J. Herrero, and Rafael Escribano \\ Instituto de Estructura de la Materia, CSIC, Serrano 123, 28006 Madrid, Spain \\ Received 2010 July 19; accepted 2010 July 17; published 2010 November 3
}

\begin{abstract}
The so-called hyperquenching technique has been applied to generate water ices containing ammonium and formate ions by sudden freezing of droplets of $\mathrm{NH}_{4} \mathrm{Cl}, \mathrm{NH}_{4} \mathrm{COOH}$, and $\mathrm{NaCOOH}$ solutions. Salt deposits were obtained after heating the ices to $210 \mathrm{~K}$ to sublimate all water content. All stages are controlled by IR transmission spectroscopy. The $\mathrm{NH}_{4}{ }^{+}$bands are very much broadened and smeared in the frozen droplets, but stand out strongly when water is eliminated. This fact hints toward the difficulty in ascertaining the presence of this species in astrophysical water-containing ices. Vapor-deposited ices of $\mathrm{NH}_{3} / \mathrm{HCOOH}$ and $\mathrm{H}_{2} \mathrm{O} / \mathrm{NH}_{3} / \mathrm{HCOOH}$ mixtures have also been studied for comparison. $\mathrm{HCOO}^{-}$and $\mathrm{NH}_{4}{ }^{+}$ions are found to be formed in small proportion even at the lowest temperature, $14 \mathrm{~K}$. By thermal processing, their IR bands become stronger, and at $210 \mathrm{~K}$, after water sublimation, they yield IR spectra similar to those obtained from hyperquenched samples. The observations are interpreted in terms of the varying ion arrangement within the solids along the warming process. A direct comparison to laboratory spectra of irradiated samples, as performed by other groups, is not straightforward.
\end{abstract}

Key words: infrared: general - line: identification - methods: laboratory

Online-only material: color figures

\section{INTRODUCTION}

The presence of ions in astronomical ices is currently a subject of interest and controversy. Observations from the short wavelength spectrometer (SWS) on board the Infrared Space Observatory (ISO; Kessler 2002; Gibb et al. 2004) and from the Spitzer Infrared Spectrograph (IRS; Werner et al. 2004) have revealed the presence of ices in the surroundings of high- and low-mass protostars as well as in quiescent dense clouds (see, for instance, Keane et al. 2001; Knez et al. 2005; Boogert et al. 2008; Zasowski et al. 2009, and references therein), and whereas the main components of these ices $\left(\mathrm{H}_{2} \mathrm{O}, \mathrm{CO}, \mathrm{CO}_{2}, \mathrm{CH}_{3} \mathrm{OH}, \mathrm{CH}_{4}\right.$, and $\mathrm{NH}_{3}$ ) have been clearly identified through characteristic absorptions in their mid-IR spectra, evidence for the presence of many other molecules and, in particular, of ionic species is not so firm. Tentative identifications of $\mathrm{OCN}^{-}, \mathrm{HCOO}^{-}$, and $\mathrm{NH}_{4}{ }^{+}$have been reported in the literature for about two decades (Grim \& Greenberg 1987; Grim et al. 1989b; Schutte et al. 1999), and hypotheses about their likely origin have been advanced. A plausible route to ion formation in interstellar ices, supported by laboratory studies, would be through highly energetic processing by photons or charged particles (Moore et al. 1983; Lacy et al. 1984; Demyk et al. 1998; Schutte \& Greenberg 1997; Palumbo et al. 2000). An alternative way could be through acid-base chemistry, which can be effective even at the very low temperatures $(<20 \mathrm{~K})$ typical of many astronomical ices (Schutte et al. 1999; Novozamsky et al. 2001; Raunier et al. 2004).

The $\mathrm{OCN}^{-}$anion was the first ionic candidate proposed to explain a feature in the spectra of astronomical ices. Its $\mathrm{CN}$ stretching vibration was assigned to the "XCN" absorption near $2167 \mathrm{~cm}^{-1}(4.26 \mu \mathrm{m})$ observed toward the massive young stellar object (YSO) W33A (Grim \& Greenberg 1987). This absorption is also observed toward many other sources (Pontoppidan et al. 2003) and, although alternative candidates to $\mathrm{OCN}^{-}$, such as organic nitriles and isonitriles (d'Hendecourt \& Allamandola 1986) or the Si-H stretching vibration (Moore et al. 1991), have been considered, extensive laboratory experiments (Schutte \&
Greenberg 1997; Demyk et al. 1998; Raunier et al. 2003, 2004; van Broekhuizen et al. 2004) support the assignment to the isocyanate ion.

Another anion likely to occur in astronomical ice mantles is $\mathrm{HCOO}^{-}$. It has been linked to the absorption at $7.41 \mu \mathrm{m}$ $\left(1359 \mathrm{~cm}^{-1}\right)$ that can be assigned to a CO stretching mode of this ion and is also present as a weak feature in the spectra of different sources (Schutte et al. 1999; Boogert et al. 2008). Acetaldehyde is also a candidate for absorption at this frequency (Schutte et al. 1999). The possible presence of $\mathrm{HCOO}^{-}$in astronomical objects should also result in absorptions at $1381 \mathrm{~cm}^{-1}(7.24 \mu \mathrm{m})$ and at $1585 \mathrm{~cm}^{-1}(6.3 \mu \mathrm{m})$. The first of these bands, caused by the $\mathrm{CH}$ deformation of the anion, coincides with the analogous band of $\mathrm{HCOOH}$ (Bisschop et al. 2007) and is indeed observed as a weak feature toward various sources (Schutte et al. 1999; Boogert et al. 2008). The second one, corresponding to the stretching mode of $\mathrm{C}-\mathrm{O}$, is blended with an intense absorption of $\mathrm{H}_{2} \mathrm{O}$ and cannot be clearly identified.

The possible occurrence of $\mathrm{NH}_{4}{ }^{+}$in astronomical ices was first advanced more than two decades ago (Grim et al. 1989b). The strong $v_{4}$ band of this ion at $1450 \mathrm{~cm}^{-1}(6.9 \mu \mathrm{m})$ has been proposed as one of the main contributors to the prominent $6.85 \mu \mathrm{m}$ absorption feature, which is ubiquitous in the spectra of ices (Keane et al. 2001; Knez et al. 2005; Zasowski et al. 2009; Boogert et al. 2008). However, this assignment is controversial (Keane et al. 2001; Schutte \& Khanna 2003; Maté et al. 2009; Moon et al. 2010). Laboratory experiments supporting it (Schutte \& Khanna 2003) require a warm-up of the ice sample to a temperature beyond $120 \mathrm{~K}$ in order to obtain the redshift in frequency and the increase in intensity needed to match the $6.85 \mu \mathrm{m}$ band, which is also found in much colder environments (Knez et al. 2005). Besides, in astronomical observations the band is in general not correlated with those attributable to the most likely negative counterions, $\mathrm{OCN}^{-}$and $\mathrm{HCOO}^{-}$, that would be present in much smaller amounts. Methanol is also considered a likely contributor to the $6.85 \mu \mathrm{m}$ absorption (Allamandola et al. 1992; Keane et al. 2001; Zasowski et al. 2009). 
In general, laboratory investigations of ions in astronomical ice analogs use as a starting point mixtures of neutral precursors, which are then irradiated or annealed to produce the charged species (Grim et al. 1989a; Schutte \& Khanna 2003; Guennoun et al. 2006; Moon et al. 2010). In a thorough study, Schutte \& Khanna (2003) photolyzed diverse mixtures of $\mathrm{H}_{2} \mathrm{O} / \mathrm{CO}_{2} /$ $\mathrm{NH}_{3} / \mathrm{O}_{2}$ with vacuum $\mathrm{UV}$ photons at $12 \mathrm{~K}$ and observed the appearance of an IR absorption feature at $\approx 1460 \mathrm{~cm}^{-1}$ attributed to $\mathrm{NH}_{4}{ }^{+}$, which shifts to the red and doubles its intensity upon warm-up to $120 \mathrm{~K}$. Guennoun et al. (2006) have reported the formation of $\mathrm{NH}_{4}^{+}, \mathrm{HCOO}^{-}$, and $\mathrm{HCO}_{3}{ }^{-}$ions through irradiation with UV photons of vapor co-deposited ice samples of $\mathrm{H}_{2} \mathrm{O}$ and dicyanoacetylene $\left(\mathrm{C}_{2} \mathrm{~N}_{4}\right)$ at $10 \mathrm{~K}$. The authors identified bands at $1576 \mathrm{~cm}^{-1}$ and $1384 \mathrm{~cm}^{-1}$ that could be due to the asymmetric $\mathrm{CO}$ stretch and to the $\mathrm{CH}$ bend of $\mathrm{HCOO}^{-}$, respectively, and also a band at $1490 \mathrm{~cm}^{-1}$ attributable to the $v_{4}$ vibration of $\mathrm{NH}_{4}{ }^{+}$. However, the absence of the $1340-1350 \mathrm{~cm}^{-1}$ peak, corresponding to the CO symmetric stretching of the formate ion casts doubt on the identification of $\mathrm{HCOO}^{-}$in the irradiated ices. In a recent work, Moon et al. (2010) investigated the possible IR signature of ammonium ions in UV irradiated $\mathrm{H}_{2} \mathrm{O} / \mathrm{NH}_{3}$ ices with a $1: 1$ ratio at $10 \mathrm{~K}$ and observed the appearance of a peak at $1515 \mathrm{~cm}^{-1}$, which they attributed to the $v_{4}$ of $\mathrm{NH}_{4}{ }^{+}$. In some cases, proton transfer reactions in the ices take place just upon mixing even at temperatures as low as $10 \mathrm{~K}$ (Schutte et al. 1999; Novozamsky et al. 2001; Raunier et al. 2004). Using IR spectroscopy, Novozamsky et al. (2001) observed the appearance of a certain amount of $\mathrm{OCN}^{-}$and $\mathrm{NH}_{4}{ }^{+}$ions in vapor-deposited $\mathrm{HNCO}$ / $\mathrm{NH}_{3}$ equimolecular mixtures at $12 \mathrm{~K}$. Upon warm up the proportion of the ions was seen to increase appreciably. In a later experiment, Raunier et al. (2004) have reported the spontaneous reaction of $\mathrm{HNCO}$ co-deposited with $\mathrm{NH}_{3} / \mathrm{H}_{2} \mathrm{O}$ mixtures in a $0.1 /(1 / 10)$ proportion, to yield $\mathrm{OCN}^{-}$and $\mathrm{NH}_{4}{ }^{+}$. Some ions are already formed at $10 \mathrm{~K}$ and their production also increases with growing deposition temperature. The spectral features of the $\mathrm{OCN}^{-}$ions in these diluted ice mixtures were seen to stand out clearly, whereas those of $\mathrm{NH}_{4}{ }^{+}$were much weaker.

These experiments not only lead to the production of ions in the ices, but also explore plausible scenarios of ion formation in astronomical environments. Nevertheless, the modifications of the ice spectra induced by reactions within the mixtures may be difficult to interpret and the assignment of newly formed features to a given species may be dubious. In a recent work of our group (Maté et al. 2009), we have taken a different approach based on the sudden freezing of droplets of aqueous solutions containing the molecular ion of interest. This procedure introduces the desired ions directly in the ice sample and allows an unambiguous study of their spectra. The method was applied to an $\mathrm{NH}_{4}{ }^{+}$-containing water ice formed from an $\mathrm{NH}_{4} \mathrm{Cl}$ solution. The $\mathrm{Cl}^{-}$atomic counterion was chosen to avoid perturbations in the IR spectra of the molecular species in the ice. The measurements showed that the $v_{4}$ band of $\mathrm{NH}_{4}{ }^{+}$, which is intense in the liquid solution, becomes weaker and spreads over a large wavelength range when embedded in the $\mathrm{H}_{2} \mathrm{O}$ ice matrix and cast doubts about the likelihood of a significant contribution of this species to the prominent $6.85 \mu \mathrm{m}$ absorption in astronomical ices. Theoretical calculations corroborated further the observed weakening of the $v_{4}$ band of $\mathrm{NH}_{4}{ }^{+}$upon interaction with the surrounding $\mathrm{H}_{2} \mathrm{O}$ molecules in the ice (Maté et al. 2009).

In the present work, we have extended our previous investigation to the study of ice samples containing either ammonium or formate or a mixture of both ions. The effects of the compact ice matrix formed in the hyperquenching experiments on the IR spectra of the two molecular ions are examined. Additional measurements are carried out on vapor-deposited $\mathrm{NH}_{3}$ / $\mathrm{HCOOH}$ mixtures and on ices of $\mathrm{H}_{2} \mathrm{O}$ with a small proportion of ammonia and formic acid. The gradual transformation of the neutral precursors into $\mathrm{NH}_{4}^{+}$and $\mathrm{HCOO}^{-}$ions through low temperature acid-base reactions in the porous vapor-deposited samples is measured in the $14-150 \mathrm{~K}$ range. The spectra of the ions in the different media are compared and discussed in light of previous laboratory experiments and available theoretical calculations. Implications for the possible detection of these ions in astrophysical observations are also discussed.

\section{EXPERIMENTAL}

Samples of water ices containing ammonium and formate ions were produced through the sudden freezing of droplets of aqueous solutions of $\mathrm{NH}_{4} \mathrm{Cl}, \mathrm{NaCOOH}$, and $\mathrm{NH}_{4} \mathrm{COOH}$ on a cold $\mathrm{Si}$ substrate located inside a vacuum chamber. This hyperquenching procedure (Mayer 1985; Johari et al 1987) leads to the formation of compact amorphous ice. A detailed description of the experimental setup can be found in previous publications (Gálvez et al. 2008; Maté et al. 2003; Carrasco et al. 2002) and only a brief account of the aspects most relevant for the present experiments is given here. The solid substrate is mounted in a $\mathrm{Cu}$ block in contact with the cold head of a closed cycle He cryostat (ARS $4 \mathrm{HW}$ ). The substrate temperature can be controlled with $1 \mathrm{~K}$ accuracy between $14 \mathrm{~K}$ and $300 \mathrm{~K}$. The vacuum chamber, which is coupled to a Vertex70 Bruker FTIR spectrometer through a purged pathway, is evacuated with a turbomolecular pump to a background pressure of $\sim 10^{-8}$ mbar. Transmission spectra of the samples were recorded, with $2 \mathrm{~cm}^{-1}$ resolution, using an MCT detector refrigerated with liquid nitrogen.

Liquid solution droplets from a room temperature pulsed valve (General Valve, series 9), usually employed for the generation of free jets and molecular beams (Abad et al. 1995), were made to impinge on the cold Si substrate placed at $\sim 15 \mathrm{~mm}$. All the salts studied in this work present a $100 \%$ dissociation in the solution at room temperature and the hydrolysis equilibrium is essentially shifted toward production of $\mathrm{NH}_{4}^{+}$and $\mathrm{HCOO}^{-}$ions. Once the droplets hit the substrate, held at $14 \mathrm{~K}$, its rate of cooling is very high and the segregation and/or ion-pairing that may occur is minimal (see Fleissner et al. 1995). After deposition, the valve was removed from the IR beam path by means of a movable feed-through. A slight $\mathrm{He}$ overpressure behind the liquid solution filling the valve improved the performance. This generation procedure does not lead to a uniform film and the thickness of the ice samples can vary somewhat among different experiments. The concentrations of the hyperquenched ices are slightly higher than those of the liquid solutions from which they are generated. This salt enrichment is probably caused by the partial evaporation of water from the droplets during their flight to the substrate. This behavior has already been observed by other authors (Mayer 1985). We have prepared liquid solutions with typical $\mathrm{H}_{2} \mathrm{O}$ /salt molecular ratios between 100:4 and $100: 8$ and have observed that the concentration of the solid deposits increases between 5\% and $20 \%$ depending on the initial concentration of the solution and on the particular salt dissolved.

We have also generated ice mixtures by co-deposition of the $\mathrm{NH}_{3}$ and $\mathrm{HCOOH}$ gases that evaporate from the solid 
$\mathrm{NH}_{4} \mathrm{COOH}$ salt kept at about $50{ }^{\circ} \mathrm{C}$ to increase its vapor pressure. Co-deposited mixtures of $\mathrm{H}_{2} \mathrm{O} / \mathrm{NH}_{3} / \mathrm{HCOOH}$ were generated in a similar way, adding water vapor through an independent line. Although the same number of $\mathrm{NH}_{3}$ and $\mathrm{HCOOH}$ molecules is present in the vapor phase in equilibrium with the solid salt, some enrichment of the lighter species $\left(\mathrm{NH}_{3}\right)$ is expected to occur in the vapor-deposited samples due to its higher velocity in an effusive flow. The estimated $\mathrm{NH}_{3} / \mathrm{HCOOH}$ ratio in the solid sample is 1.3:1.

Spectra were recorded at the beginning of each experiment when the substrate was held at $14 \mathrm{~K}$. Sublimation of water was induced by warming the samples up to $210 \mathrm{~K}$. This was completed after a few minutes, as shown by the disappearance of the water bands in the spectrum. The samples were then cooled again to $14 \mathrm{~K}$ and the spectra of the crystalline salts, characterized by narrow features, were recorded. It should be noted that, after evaporation of the water, all the bands observed in the mid-IR region under study correspond to vibrations of the molecular ions $\left(\mathrm{NH}_{4}^{+}\right.$and $\left.\mathrm{HCOO}^{-}\right)$in the crystals.

Spectra of the initial liquid solutions used in the hyperquenching procedure were also measured for reference in a separate cell at room temperature.

Although only neutral species can be present in the vapor phase during the generation process of co-deposited mixtures, we observed that even at $14 \mathrm{~K}$ the spectra showed features corresponding to $\mathrm{HCOO}^{-}$and $\mathrm{NH}_{4}{ }^{+}$ions. The warm-up of the mixtures to $150 \mathrm{~K}$, below the sublimation temperature of pure $\mathrm{NH}_{3}$ and $\mathrm{HCOOH}$, leads to the complete transformation of the neutral species to ions.

The water concentration in the ice mixtures, either generated by hyperquenching or by vapor deposition, was estimated by reference to the $3 \mu \mathrm{m}$ water band intensity value reported by Mastrapa et al. (2009) at $15 \mathrm{~K}, A\left(\mathrm{H}_{2} \mathrm{O}\right)=1.9 \times 10^{-16} \mathrm{~cm}$ molecule ${ }^{-1}$. The concentration of the other species was evaluated from the spectra of the salt deposits that remain after sublimation of water. For $\mathrm{NH}_{4} \mathrm{Cl}$, we could use a literature reference, the intensity of the $v_{4}$ band of $\mathrm{NH}_{4}{ }^{+}$at $\sim 1409 \mathrm{~cm}^{-1}$ given by Schutte \& Khanna (2003), $A\left(v_{4}, \mathrm{NH}_{4}{ }^{+}\right)=4.4 \times 10^{-17} \mathrm{~cm}$ molecule ${ }^{-1}$. For the $\mathrm{NaCOOH}$ and $\mathrm{NH}_{4} \mathrm{COOH}$ salts, we used the integrated intensity of the $v_{2}$ band at $\sim 1600 \mathrm{~cm}^{-1}$ of the common anion $\mathrm{HCOO}^{-}$, for which we measured a band strength, $A\left(v_{2}, \mathrm{HCOO}^{-}\right)=1.3 \times 10^{-16} \mathrm{~cm}$ molecule ${ }^{-1}$, as described in the following: starting from a $\mathrm{NH}_{3} / \mathrm{HCOOH}$-deposited sample, we determined the amount of neutral species from the strength of the $\mathrm{NH}_{3} \sim 3375 \mathrm{~cm}^{-1}$ band using the reference value by d'Hendecourt \& Allamandola (1986) for pure ammonia ice at $10 \mathrm{~K}, A\left(\mathrm{NH}_{3}, 3100 \mathrm{~cm}^{-1}\right)=1.1 \times 10^{-17} \mathrm{~cm}$ molecule ${ }^{-1}$. The fraction of ions in the sample was estimated to be of the order of $15 \%$, as given by the $\mathrm{HCOO}^{-}$-band intensity ratio between measurements at $150 \mathrm{~K}$, where no neutral species remain, and at $14 \mathrm{~K}$. This procedure assumes that the absorption coefficients do not change with temperature. Using these values and the estimated $\mathrm{NH}_{3}$ enrichment in the vapor-deposited samples of 1.3:1, the total concentration of $\mathrm{N}$-containing species and C-containing species could be determined, and from this result we evaluated the above-mentioned absolute band strength of the $v_{2}$ formate band.

\section{RESULTS AND DISCUSSION}

\subsection{Hyperquenching Experiments}

Figure 1 summarizes the results obtained using the hyperquenching technique on samples of the three salts investigated,

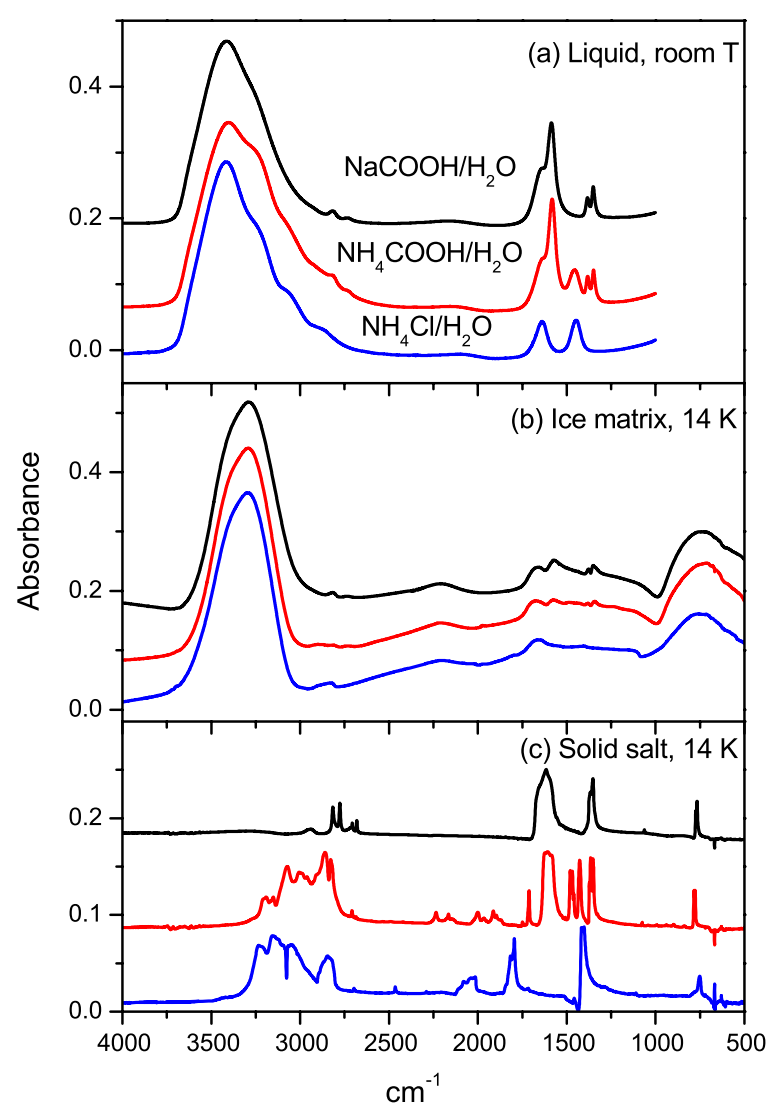

Figure 1. Transmission IR spectra of (a) (7:100) liquid solutions of NaCOOH: $\mathrm{H}_{2} \mathrm{O}, \mathrm{NH}_{4} \mathrm{COOH}: \mathrm{H}_{2} \mathrm{O}$, and $\mathrm{NH}_{4} \mathrm{Cl}: \mathrm{H}_{2} \mathrm{O}$ at ambient temperature; (b) $(8: 100)\left(\mathrm{NaCOOH}: \mathrm{H}_{2} \mathrm{O}\right),(7: 100)\left(\mathrm{NH}_{4} \mathrm{COOH}: \mathrm{H}_{2} \mathrm{O}\right)$, and $(9: 100)$ $\left(\mathrm{NH}_{4} \mathrm{Cl}: \mathrm{H}_{2} \mathrm{O}\right)$ solids deposited by hyperquenching at $14 \mathrm{~K}$; (c) salt residues obtained after heating the samples in panel (b) to $210 \mathrm{~K}$ and cooling them to $14 \mathrm{~K}$. Spectra are offset for clarity.

(A color version of this figure is available in the online journal.)

prepared in a concentration range expected to be representative of astronomical ices. The upper panel presents the spectra of the liquid solutions at room temperature. Liquid droplets from solutions of the concentration indicated in the figure were made to impinge on the $14 \mathrm{~K} \mathrm{Si}$ substrate where they instantly froze yielding amorphous solids, which contain the desired ions. The corresponding spectra are collected in the middle panel. The spectra are dominated by the absorptions of amorphous solid water (ASW), and the weak features due to the $\mathrm{NH}_{4}{ }^{+}$and $\mathrm{HCOO}^{-}$ ions are barely appreciable at first sight. The presence of the molecular ions is put into manifest by heating the substrate to $210 \mathrm{~K}$, which leads to water sublimation and induces the precipitation of the salts. The spectra of the solids formed by cooling the precipitated salts at $14 \mathrm{~K}$ are shown in the lowest panel of Figure 1, where distinct narrow bands of the ions are observed.

The spectral interval between $2000 \mathrm{~cm}^{-1}$ and $1100 \mathrm{~cm}^{-1}$ has been enlarged in Figure 2 to facilitate the discussion. The characteristic bands of ammonium and formate ions used for their tentative identification in astronomical ice mantels pertain to this region. An assignment of the bands in this interval is given in Table 1. In general, the $\mathrm{NH}_{4}{ }^{+}$bands display stronger variations between the different media than those of $\mathrm{HCOO}^{-}$. The ammonium $v_{4}$ deformation at $1409 \mathrm{~cm}^{-1}$ in the spectrum of $\mathrm{NH}_{4} \mathrm{Cl}$ (solid salt, bottom panel) is shifted and split into three components at 1426,1469 , and $1480 \mathrm{~cm}^{-1}$ in that of $\mathrm{NH}_{4} \mathrm{COOH}$, indicating a less symmetrical environment for the $\mathrm{NH}_{4}{ }^{+}$ions in ammonium formate. Likewise, the $v_{4}+v_{5}$ band, 
Table 1



\begin{tabular}{|c|c|c|c|c|c|c|c|c|c|}
\hline \multirow[t]{2}{*}{ Mode } & \multicolumn{3}{|c|}{$\mathrm{H}_{2} \mathrm{O} / \mathrm{NH}_{4} \mathrm{Cl}$} & \multicolumn{3}{|c|}{$\mathrm{H}_{2} \mathrm{O} / \mathrm{NaCOOH}$} & \multicolumn{3}{|c|}{$\mathrm{H}_{2} \mathrm{O} / \mathrm{NH}_{4} \mathrm{COOH}$} \\
\hline & Solution & Ice & Salt $^{\mathrm{a}}$ & Solution & Ice & Salt $^{\mathrm{a}}$ & Solution & Ice & Salt $^{\mathrm{a}}$ \\
\hline $\mathrm{NH}_{4}^{+}\left(v_{4}+v_{5}\right)$ & $\ldots$ & $\begin{array}{c}1811(5.52) \\
1796^{\mathrm{b}}(5.57)\end{array}$ & $\begin{array}{l}1818(5.50) \\
1794(5.57)\end{array}$ & $\ldots$ & $\ldots$ & $\cdots$ & $\ldots$ & $\ldots$ & $\begin{array}{l}1997(5.01) \\
1911(5.23)\end{array}$ \\
\hline $\mathrm{H}_{2} \mathrm{O}\left(v_{2}\right.$, bend $)$ & $1640(6.10)$ & $1662(6.02)$ & $\ldots$ & $1640(6.10)$ & $1662(6.02)$ & $\ldots$ & $1642(6.09)$ & $1673(5.98)$ & \\
\hline $\mathrm{HCOO}^{-}\left(v_{4}, \mathrm{CO}\right.$ a-st $)$ & $\ldots$ & $\ldots$ & $\ldots$ & $1586(6.30)$ & $1575(6.35)$ & $1618(6.18)$ & $1589(6.29)$ & $1572(6.36)$ & $1607(6.22)$ \\
\hline $\mathrm{NH}_{4}{ }^{+}\left(v_{4}\right.$, bend $)$ & $1446(6.91)$ & $1400^{\mathrm{a}}(7.14)$ & $1409(7.10)$ & $\ldots$ & $\ldots$ & $\ldots$ & $1459(6.85)$ & $1487^{\mathrm{c}}(6.72)$ & $\begin{array}{l}1480(6.76) \\
1469(6.81) \\
1426(7.01)\end{array}$ \\
\hline $\mathrm{HCOO}^{-}\left(v_{5}, \mathrm{CH}\right.$ bend $)$ & $\ldots$ & $\ldots$ & $\ldots$ & $1384(7.22)$ & $1377(7.26)$ & $1367(7.31)$ & $1384(7.22)$ & $1379(7.25)$ & $1367(7.31)$ \\
\hline $\mathrm{HCOO}^{-}\left(v_{4}, \mathrm{CO}\right.$ s-st $)$ & $\ldots$ & $\ldots$ & $\ldots$ & $1349(7.41)$ & $1351(7.40)$ & $1354(7.38)$ & $1349(7.41)$ & $1342(7.45)$ & $1352(7.40)$ \\
\hline
\end{tabular}

Notes. Typical uncertainty of $\sim 5 \mathrm{~cm}^{-1}$. Only the vibrations with special astronomical relevance are quoted (wavelength in $\mu \mathrm{m}$ within parenthesis).

a After water evaporation.

b Very weak features.

c Broad band.

with a maximum at $1794 \mathrm{~cm}^{-1}$ and a shoulder at $1818 \mathrm{~cm}^{-1}$ in $\mathrm{NH}_{4} \mathrm{Cl}$ is blueshifted $\left(\sim 1911 \mathrm{~cm}^{-1}\right)$ in the formate salt. In the aqueous solution, the combination bands of $\mathrm{NH}_{4}^{+}$are not appreciated, but the $v_{4}$ band is clearly visible at $\sim 1450 \mathrm{~cm}^{-1}$. In the ice matrix, the $v_{4}$ band broadens and virtually disappears, as discussed at length in Maté et al. (2009). In contrast, the spectral features of $\mathrm{HCOO}^{-}$persist in all the environments. The most intense band is the $v_{4}$ asymmetric $\mathrm{CO}$ stretch, located at $\sim 1610 \mathrm{~cm}^{-1}$ in the spectra of the salts, at $\sim 1585 \mathrm{~cm}^{-1}$ in the liquid solution, and at $\sim 1575 \mathrm{~cm}^{-1}$ in those of the ices. In the latter two cases, the band is blended with the $v_{2}$ bending of water at $\sim 1645 \mathrm{~cm}^{-1}$. Two more bands of $\mathrm{HCOO}^{-}$are present in all the samples, namely, the $v_{3}$ symmetric $\mathrm{CO}$ stretch and the $v_{5} \mathrm{CH}$ bend, which give peaks in the $1340-1350 \mathrm{~cm}^{-1}$ and $1370-1385 \mathrm{~cm}^{-1}$ intervals, respectively.

Theoretical calculations, available in the literature, can help rationalize these experimental observations. The water molecules surrounding the molecular ions in the ices can inhibit and distort their internuclear motions and, furthermore, due to the strong dipole moment of $\mathrm{H}_{2} \mathrm{O}$, they will affect the charge distributions in the different bonds and change the IR activity of the associated vibrations. Density functional theory (DFT) calculations of $\mathrm{HCOO}^{-}$and $\mathrm{NH}_{4}{ }^{+}$ions embedded in water clusters of variable size (Park \& Woon 2006) can account for the frequency of the three formate bands $\left(v_{3}, v_{4}\right.$, and $\left.v_{5}\right)$ discussed in the previous paragraph (see Table 1). Their relative intensities in the ice spectra are also well reproduced by the results of Park \& Woon, yielding, in decreasing intensity order, the asymmetric CO stretch $\left(1575 \mathrm{~cm}^{-1}\right)$, its symmetric counterpart $\left(1345 \mathrm{~cm}^{-1}\right)$, and the $\mathrm{CH}$ bending $\left(1380 \mathrm{~cm}^{-1}\right)$. The calculations also show that the unsymmetrical environment of the clusters breaks the degeneracy of the $\mathrm{NH}_{4}{ }^{+} v_{4}$ band which appears split into three peaks separated by tens of $\mathrm{cm}^{-1}$. Recent DFT calculations by Maté et al. (2009) using the SIESTA suite of programs, specially designed for the study of solid structures, showed that the intensity of the ammonium $v_{4}$ deformation band of $\mathrm{NH}_{4} \mathrm{Cl}$ trapped in ice decreases markedly with respect to that of solid $\mathrm{NH}_{4} \mathrm{Cl}$ due to the decrease in polarization along the bending mode directions of $\mathrm{NH}_{4}{ }^{+}$induced by the strongly coordinated surrounding water molecules. In addition, a number of slightly different configurations with similar energies, also accessible to the $\mathrm{NH}_{4}{ }^{+}$within the ice, will give rise to a substantial broadening of this band. Very large broadenings of intense IR bands are well known for the structurally similar $\mathrm{H}_{3} \mathrm{O}^{+}$cation in aqueous condensed phases, where the ion is linked by strong hydrogen

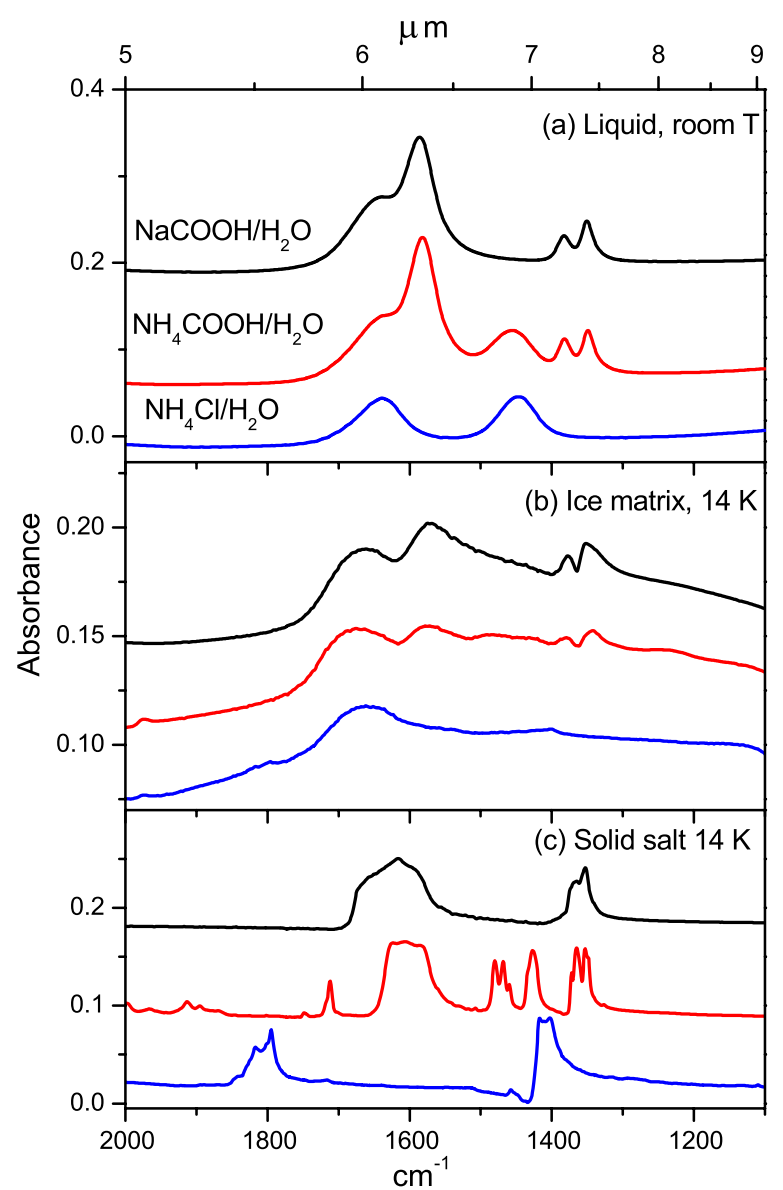

Figure 2. Magnification of the $2000-1100 \mathrm{~cm}^{-1}$ region of the spectra represented in Figure 1.

(A color version of this figure is available in the online journal.)

bonds to neighboring water molecules, so that the protons can oscillate in a very anharmonic potential modulated by the heavier atoms (Marx et al. 1999; Zundel 2000; Martín-Llorente et al. 2006). Although similar calculations are not available for formate ions in ice structures, it is worth noting that the possible configurations of $\mathrm{HCOO}^{-}$in the ices will be geometrically much more constrained due to the predominance of heavier atoms in the anion as compared with the light and mobile $\mathrm{NH}_{4}{ }^{+}$. Consequently, the weakening and broadening should be smaller in the formate bands, which would justify the survival of these bands 


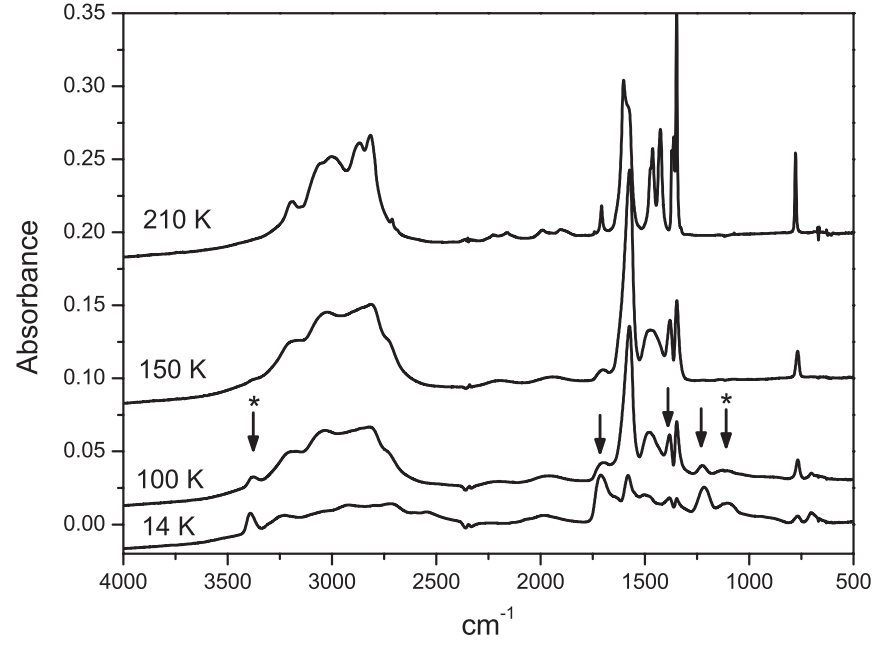

Figure 3. Spectral evolution of a vapor co-deposited 1.3:1 $\mathrm{NH}_{3} / \mathrm{HCOOH}$ ice mixture as a function of temperature. At $14 \mathrm{~K}$, there are $\sim 15 \%$ of ionic species present. The $\mathrm{NH}_{3}$ main bands appear at $\sim 3375 \mathrm{~cm}^{-1}$ and $\sim 1070 \mathrm{~cm}^{-1}$ (indicated by arrows with asterisk). $\mathrm{HCOOH}$ has several bands in this IR range; the bands especially interesting for this work, below $2000 \mathrm{~cm}^{-1}$, are at $\sim 1700 \mathrm{~cm}^{-1}, \sim 1380 \mathrm{~cm}^{-1}$, and $\sim 1210 \mathrm{~cm}^{-1}$ (marked by bare arrows). The $\mathrm{HCOO}^{-}$and $\mathrm{NH}_{4}+$ bands can be consulted in Table 1. Spectra are offset for clarity.

in the ice samples in contrast with the disappearance of the $v_{4}$ band of ammonium.

There may be an apparent contradiction between the results of this work, obtained by the hyperquenching technique, and a previous laboratory investigation which proposed the assignment of a strong peak at $\sim 1460 \mathrm{~cm}^{-1}$ to the $\mathrm{NH}_{4}{ }^{+} v_{4}$ band (Schutte \& Khanna 2003). The reader is referred to our recent publication (Maté et al. 2009), where this subject is discussed at length. The present investigation adds more evidence arising from the ammonium formate experiment to that available in Maté et al. for ammonium chloride, with similar conclusions concerning the lack of a strong ammonium ion band at $6.85 \mu \mathrm{m}$ in astrophysically relevant conditions. Moreover, the present observations of the formate bands, together with the theoretical calculations of Park \& Woon (2006) mentioned above, pose a firm constrain on the proposed assignment of the observed features at 1576 and $1384 \mathrm{~cm}^{-1}$ by Guennoun et al. (2006) to this anion, in view of the lack of the $1350 \mathrm{~cm}^{-1}$ band, expected to be more intense than the lowest vibration of this group.

\subsection{Comparison of Vapor Deposition and Hyperquenching Techniques}

Further information can be derived from the production of $\mathrm{NH}_{4}{ }^{+}$and $\mathrm{HCOO}^{-}$ions generated in low temperature acid-base reactions of $\mathrm{NH}_{3}$ and $\mathrm{HCOOH}$ in the absence of water. Figure 3 shows the results of the vapor deposition and warm-up of a mixture of formic acid and ammonia. In spite of the fact that only neutral $\mathrm{NH}_{3}$ and $\mathrm{HCOOH}$ molecules enter the vacuum chamber, spectral features of $\mathrm{NH}_{4}{ }^{+}$and $\mathrm{HCOO}^{-}$are already visible in the freshly deposited sample at $14 \mathrm{~K}$ displayed in the lower trace of the figure. The corresponding bands are marked by arrows and enumerated in the figure caption. The proportion of ions in the $14 \mathrm{~K}$ sample is estimated to be $\sim 15 \%$, as described above. Given the low mobility of molecules at this temperature, the proton transfer reaction must be largely restricted to neighboring ammonia and formic acid molecules. Heating the sample at a rate of $10 \mathrm{~K}$ minute $^{-1}$ leads to a gradual transformation of the neutral molecules into ionic species. At $150 \mathrm{~K}$ practically all

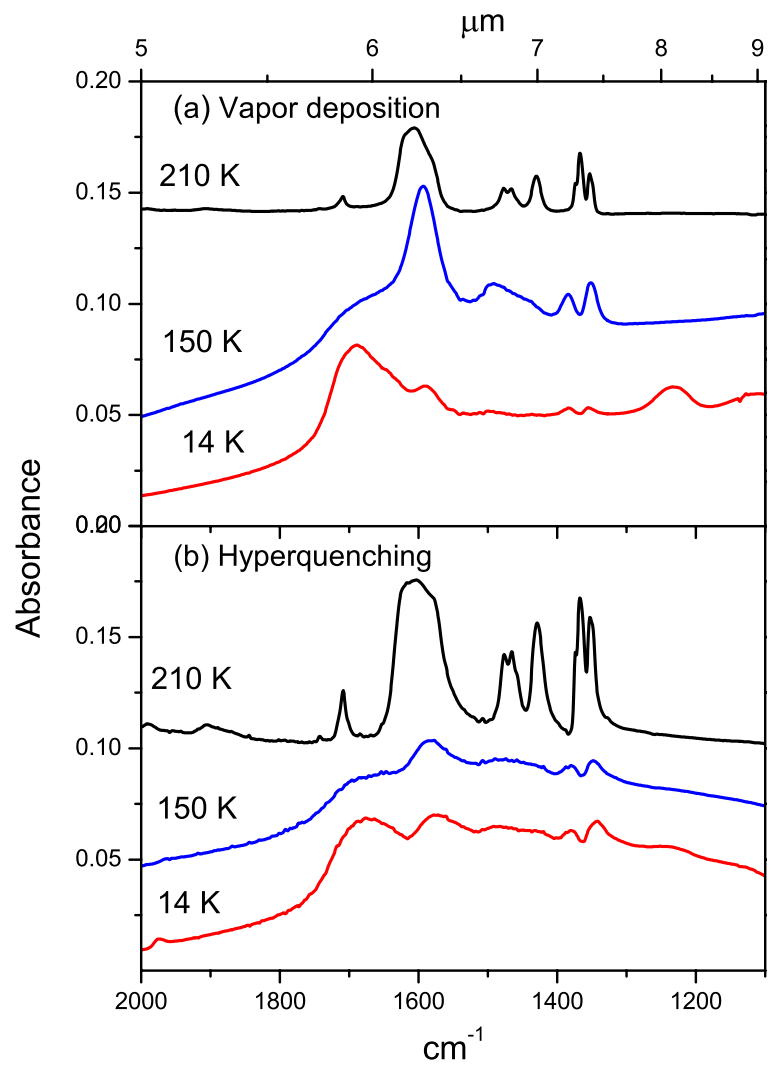

Figure 4. (a) Transmission spectra of a 100:2.6:2 $\mathrm{H}_{2} \mathrm{O} / \mathrm{NH}_{3} / \mathrm{HCOOH}$ codeposited sample generated at $14 \mathrm{~K}$ and heated to $150 \mathrm{~K}$ and $210 \mathrm{~K}$; (b) transmission spectra of a 100:7 $\mathrm{H}_{2} \mathrm{O} / \mathrm{NH}_{4} \mathrm{COOH}$ solid generated by hyperquenching at $14 \mathrm{~K}$ and heated to $150 \mathrm{~K}$ and $210 \mathrm{~K}$. Spectra are offset for clarity.

(A color version of this figure is available in the online journal.)

neutrals have been transformed, and at $210 \mathrm{~K}$ the spectrum of the $\mathrm{NH}_{4} \mathrm{COOH}$ salt is obtained.

We have also studied the formation of ammonium and formate ions in diluted vapor co-deposited samples, with $\mathrm{H}_{2} \mathrm{O} / \mathrm{NH}_{3} / \mathrm{HCOOH}=100 / 2.6 / 2$. Figure 4 , top, shows the $2000-1100 \mathrm{~cm}^{-1}$ spectral range of a vapor-deposited sample at $14 \mathrm{~K}$ and the evolution of its spectrum after heating to $150 \mathrm{~K}$ and $210 \mathrm{~K}$. The spectra are in excellent agreement with those measured by Schutte et al. (1999) in an analogous experiment using a mixture of similar composition. Although not shown in the figure we observed the change in the profile of the main absorption band of $\mathrm{H}_{2} \mathrm{O}$ at $\sim 3000-3600 \mathrm{~cm}^{-1}$ reflecting the crystallization of the ice upon heating. While two bands of formic acid at $\sim 1700 \mathrm{~cm}^{-1}$ (blended with the bending mode of $\mathrm{H}_{2} \mathrm{O}$ at $1645 \mathrm{~cm}^{-1}$ ) and $\sim 1230 \mathrm{~cm}^{-1}$ dominate the spectrum at $14 \mathrm{~K}$, the features of the formate ion at 1580,1380 , and $1350 \mathrm{~cm}^{-1}$ are already appreciable. The $v_{4}$ band of $\mathrm{NH}_{4}{ }^{+}$ at $1480 \mathrm{~cm}^{-1}$ is too weak to be clearly discernible at this temperature. Given the high dilution of $\mathrm{NH}_{3}$ and $\mathrm{HCOOH}$ in the samples, the coincidence of these molecules in close positions is expected to be rare in the ice matrix, and taking into account the low molecular mobility expected at $14 \mathrm{~K}$, it seems likely that water molecules and their associated $\mathrm{H}_{3} \mathrm{O}^{+}$and $\mathrm{OH}^{-}$ions will take part in the proton exchange reactions leading to the formation of the formate and ammonium ions as pointed out by Moon et al. (2010). In fact the DFT calculations of Park \& Woon (2006) show that in $\mathrm{HCOOH} \cdot\left(\mathrm{H}_{2} \mathrm{O}\right)_{n}$ clusters a proton can be spontaneously transferred if a sufficient number of 
$\mathrm{H}_{2} \mathrm{O}$ molecules is present (in their work the authors report an optimized $\mathrm{HCOO}^{-} \mathrm{H}_{3} \mathrm{O}^{+} \cdot\left(\mathrm{H}_{2} \mathrm{O}\right)_{14}$ structure). Upon warming to $150 \mathrm{~K}$, the $\mathrm{HCOOH}$ bands disappear (middle trace) and those of $\mathrm{HCOO}^{-}$and $\mathrm{NH}_{4}{ }^{+}$rise markedly indicating a total transformation of the neutral precursors into their ionic counterparts. This is the most intense spectrum of the ions in the ices obtained in the present work and, in fact, the only one for which the $v_{4}$ band of $\mathrm{NH}_{4}{ }^{+}$is clearly visible. It is worth noting that the peak of the band is located at $1490 \mathrm{~cm}^{-1}$ and not redshifted to $1420 \mathrm{~cm}^{-1}$ as found in the high temperature experiments of Schutte \& Khanna (2003) with processed ice mixtures. In the bottom panel of the same figure, spectra of the hyperquenched $\mathrm{NH}_{4} \mathrm{COOH}: \mathrm{H}_{2} \mathrm{O}$ sample commented on above are also represented for comparison. In the sample produced by this technique, where the ions are already present in the ices at $14 \mathrm{~K}$, little change is observed after heating to $150 \mathrm{~K}$. A reshaping of the peaks in the $1750-1500 \mathrm{~cm}^{-1}$, probably caused by the modification in the band contour of the bending mode of water $\left(\sim 1645 \mathrm{~cm}^{-1}\right)$ upon phase transition, can be seen, but no significant variation is observed in the intensity of the $\mathrm{HCOO}^{-}$ peaks.

In the $150 \mathrm{~K}$ traces, the vapor-deposited spectra present much higher intensity features than their hyperquenching counterpart. This is remarkable, especially considering that the concentration of $\mathrm{HCOO}^{-}$and $\mathrm{NH}_{4}{ }^{+}$in the ice is just $2 \%$ as compared with $7 \%$ for the hyperquenched sample. The intrinsic intensities of the ion bands in the vapor-deposited ice are thus a factor of $\sim 10$ higher than those in the hyperquenching matrix. We can put forward a possible explanation to this difference based on the distinct environment of the ions in the two ices. As discussed in Maté et al. (2009) and Fernández-Torre et al. (2005), the intensity of an infrared absorption for a given species in the solid phase is expected to be larger the higher the ionic character of the bonds involved in the vibration, and therefore the higher the corresponding dipole moment variation. If the individual ions are strongly coordinated to the surrounding water molecules, the high polarity of $\mathrm{H}_{2} \mathrm{O}$ will contribute to a large spread of the electronic charge along the strong hydrogen bonds formed, which finally make the local dipoles weaker and leads to a decrease of the IR absorption intensity. If, on the other hand, $\mathrm{NH}_{4}{ }^{+}$and $\mathrm{HCOO}^{-}$ions within the ices can interact more closely with each other and be more weakly affected by the water environment, the ionic character of the bonds will be larger and the band intensities higher. The hyperquenched samples are expected to retain much of the dense, disordered structure of the liquid solution, with individual ions surrounded by solvation spheres of water molecules. In contrast, amorphous ices formed by vapor deposition at $14 \mathrm{~K}$ have a different morphology and build microporous, lowdensity $\left(0.6-0.7 \mathrm{~g} \mathrm{~cm}^{-3}\right)$ structures (see, for instance, Baragiola 2003; Raut et al. 2007; Herrero et al. 2010, and references therein). As mentioned above, in the co-deposited $\mathrm{H}_{2} \mathrm{O} / \mathrm{NH}_{3}$ / $\mathrm{HCOOH}$ samples only a small amount of ions is present at $14 \mathrm{~K}$, most probably through some proton transfer involving water molecules. With increasing temperature, the molecular mobility raises and $\mathrm{NH}_{3}$ and $\mathrm{HCOOH}$ molecules could diffuse within the porous ice structure incrementing the probability of forming larger ionic networks that would survive the collapse of the microporous structure and eventual crystallization of the water ice upon further heating. In support of this hypothesis, we compare in Figure 4 the spectra of the corresponding salt residues after heating the substrate to $210 \mathrm{~K}$. The small intensity variations in the water evaporation process for the vapor-deposited samples suggest that formate and ammonium within the ice were already in a truly ionic environment. In contrast, the remarkable intensity increase of the ion bands in this process for the hyperquenched samples points to the previous existence of a diffuse polarizability cloud along the bonds in ammonium and formate, possibly shielded from each other by a number of solvating $\mathrm{H}_{2} \mathrm{O}$ molecules, which disappears when water is sublimated. Finally, it is worth noting the almost identical structure of the $210 \mathrm{~K}$ traces in both techniques, but for the strongest absorbance recorded for the higher concentration hyperquenched sample.

\section{ASTROPHYSICAL IMPLICATIONS}

It is generally assumed that ice mantels on interstellar grains are formed through accretion of atoms and molecules followed by diffusion and chemical reactions on the grain surface (Tielens \& Hagen 1982; Ehrenfreund \& Fraser 2002; Cuppen \& Herbst 2007, and references therein). It is further believed that the resulting water network, which dominates the composition of the ices, builds largely compact amorphous structures (Ehrenfreund \& Fraser 2002; Oba et al. 2009), although the occurrence of open, porous morphologies cannot be excluded, given the diversity of astronomical ice environments (Kouchi $\&$ Yamamoto 1995). The measurements on the hyperquenched samples described throughout this work, as well as available theoretical calculations (Maté et al. 2009), indicate that in compact structures the absorption bands of the ions will be significantly weakened through strong interactions with the surrounding water molecules. This effect has been found to be specially pronounced in the case of $\mathrm{NH}_{4}{ }^{+}$.

In the observationally relevant $5-8 \mu \mathrm{m}\left(2000-1250 \mathrm{~cm}^{-1}\right)$ interval, the spectral features of $\mathrm{HCOO}^{-}$, in a $7 \%$ dilution with respect to $\mathrm{H}_{2} \mathrm{O}$, are still visible in the hyperquenched ice matrix. Schutte et al. (1999) proposed the assignment of the $7.41 \mu \mathrm{m}\left(1350 \mathrm{~cm}^{-1}\right)$ weak feature in the SWS-ISO spectrum of the obscured massive YSO W33A to this ion. A concomitant weak absorption at $7.24 \mu \mathrm{m}\left(1381 \mathrm{~cm}^{-1}\right)$ in the spectrum of the same object was assumed to be formed by contributions from the $\mathrm{CH}$ bending mode of $\mathrm{HCOOH}$ and $\mathrm{HCOO}^{-}$. The third, and most intense band of the formate ion, expected at $6.3 \mu \mathrm{m}\left(1585 \mathrm{~cm}^{-1}\right)$, would be blended with the intense $\mathrm{H}_{2} \mathrm{O}$ absorption at $6 \mu \mathrm{m}\left(1645 \mathrm{~cm}^{-1}\right)$ and cannot be seen as a separate peak, but has been occasionally invoked as a possible candidate to account for an excess absorption in this wavelength range (Zasowski et al. 2009). The present results are consistent with this interpretation. The just mentioned two weak features at $\sim 7.21 \mu \mathrm{m}$ and $\sim 7.41 \mu \mathrm{m}$ have been recently identified, with lower resolution, in the IRS Spitzer spectra of a number of lowmass YSOs (Boogert et al. 2008).

The $v_{4}$ deformation band of $\mathrm{NH}_{4}{ }^{+}$has been proposed (Schutte \& Khanna 2003) to be an important contributor to the prominent $6.85 \mu \mathrm{m}\left(1470 \mathrm{~cm}^{-1}\right)$ band observed toward most sources (Boogert et al. 2008), but the results of this work show that the band virtually disappears in the spectra of the compact (hyperquenched) ice samples. Although acid-base chemistry leading to the formation of ammonium ions is possible at very low temperatures, a relatively intense feature attributable to the $v_{4}$ mode of $\mathrm{NH}_{4}{ }^{+}$is only found in laboratory measurements with vapor-deposited samples, at comparatively high temperatures $(>100 \mathrm{~K})$ and, less conclusively, in irradiated mixtures. In the latter case, the feature of interest differs more in shape between experiments and presents sometimes a mismatch in frequency 
with respect to the astronomical data (see, for instance, Figure 4 of this work; Schutte et al. 1999; Schutte \& Khanna 2003; van Broekhuizen et al. 2004; Raunier et al. 2004; Guennoun et al. 2006; Moon et al. 2010). Although the line of sight toward many YSOs may contain ices of very different temperatures, the recent observations of a prominent $6.85 \mu \mathrm{m}$ band in cold dark clouds toward the CK2 and Elias 16 background stars (Knez et al. 2005) indicate that probably neither thermal nor radiative processing of the ices is required for the generation of the carriers of this band. Although a contribution of $\mathrm{NH}_{4}{ }^{+}$cannot be rigorously excluded, the previous considerations suggest that it should probably not be large.

\section{SUMMARY AND CONCLUSIONS}

Ammonium and formate ions can be directly introduced into ice matrices through hyperquenching of water droplets of diluted salt solutions. In these compact matrices the midIR absorptions of the ions are considerably weakened through interaction with the water molecules in the ice framework. The IR spectral signature of $\mathrm{HCOO}^{-}$(three bands, at $\sim 1575$, 1380 , and $1345 \mathrm{~cm}^{-1}$, with a characteristic pattern of relative intensities) is preserved in all the ice samples investigated. But in astrophysical objects, the bands at $1575 \mathrm{~cm}^{-1}$ and $1380 \mathrm{~cm}^{-1}$ can be obscured by absorptions of $\mathrm{H}_{2} \mathrm{O}$ and $\mathrm{HCOOH}$, respectively, that can hamper the unambiguous identification of the ion. The $v_{4}$ band of $\mathrm{NH}_{4}{ }^{+}$at $\approx 1450 \mathrm{~cm}^{-1}$ becomes weaker and broader in the ice samples and is practically indiscernible at realistic concentrations in compact ices. Even if the ion were present in such environments it would probably be undetectable in astronomical observations.

Low temperature acid-base chemistry in $\mathrm{NH}_{3} / \mathrm{HCOOH}$ equimolecular mixtures takes place to some extent even at very low temperatures $(14 \mathrm{~K})$. Spectral features coincident with those of the ions directly introduced in the ice matrices are seen to evolve and dominate entirely the samples for $T>120 \mathrm{~K}$. Our results also show that porous vapor-deposited ices, containing a small proportion of $\mathrm{NH}_{3}$ and $\mathrm{HCOOH}$ in water, offer hints of the ionic spectral pattern at $14 \mathrm{~K}$. Thermal processing of these ices leads to a marked enhancement of the ion spectral bands, which turn out to be much more intense than those in the compact ice matrix, suggesting that ionic $\mathrm{NH}_{4}{ }^{+} \mathrm{HCOO}^{-}$networks can be formed within these ices upon heating. An astronomical environment with porous, thermal processed ices could thus provide a better opportunity for the observation of ammonium and formate ions.

Except for their absolute intensities, the spectral patterns of the ions in hyperquenched droplets, and those obtained through thermal processing of vapor-deposited samples are very similar. The agreement is not so good with the spectra attributed to $\mathrm{HCOO}^{-}$and $\mathrm{NH}_{4}{ }^{+}$in irradiated ice mixtures, where differences in shape or frequency, or even the lack of an expected ionic feature are sometimes found.

This research has been carried out with funding from the Spanish Ministry of Education, Project FIS2007-61686. O.G. acknowledges financial support from CSIC, "JAE-Doc" program. V.J.H. acknowledges support from Consolider Project "Astromol," CSD2009-0038.

\section{REFERENCES}

Abad, L., Bermejo, D., Herrero, V. J., Santos, J., \& Tanarro, I. 1995, Rev. Sci. Instrum., 66, 3826
Allamandola, L. J., Sandford, S. A., Tielens, A. G. G. M., \& Herbst, T. M. 1992, ApJ, 399, 134

Baragiola, R. A. 2003, in Water in Confined Geometries, ed. J. P. Devlin \& V. Buch (Berlin: Springer)

Bisschop, S. E., Fuchs, G. W., Boogert, A. C. A., van Dishoeck, E. F., \& Linnartz, H. 2007, A\&A, 470, 749

Boogert, A. C. A., et al. 2008, ApJ, 678, 985

Carrasco, E., Castillo, J. M., Escribano, R., Herrero, V. J., Moreno, M. A., \& Rodríguez, J. 2002, Rev. Sci. Instrum., 73, 3469

Cuppen, H. M., \& Herbst, E. 2007, ApJ, 668, 294

Demyk, K., Dartois, E., d'Hedecourt, L., Jourdain de Muizon, M., Heras, A. M., \& Breitfellner, M. 1998, A\&A, 339, 553

d'Hendecourt, L. B., \& Allamandola, L. J. 1986, A\&A, 64, 453

Ehrenfreund, P., \& Fraser, H. 2002, in NATO ASI Series, Solid State Astrochemistry, ed. V. Pirronello \& J. Krelovski (Dordrecht: Kluwer)

Fernández-Torre, D., Escribano, R., Archer, T., Pruneda, J. M., \& Artacho, E. 2005, J. Phys. Chem. A, 108, 10535

Fleissner, G., Hallbrucker, A., \& Mayer, E. 1995, J. Chem. Phys., 99, 8401

Gálvez, O., Maté, B., Herrero, V. J., \& Escribano, R. 2008, Icarus, 197, 599

Gibb, E. L., Whittet, D. C. B., Boogert, A. C. A., \& Tielens, A. G. G. 2004, ApJS, 151,35

Grim, R., Greenberg, J. M., Schutte, W., \& Schmitt, B. 1989a, ApJ, 341, L87

Grim, R. J. A., \& Greenberg, J. M. 1987, ApJ, 321, L91

Grim, R. J. A., Greenberg, J. M., de Croot, M. S., Bass, F., Schutte, W. A., \& Schmitt, B. 1989b, A\&A, 78, 161

Guennoun, Z., Pietri, N., Couturier-Tamburelli, I., \& Aycard, J. P. 2006, J. Phys. Chem. A, 110, 7738

Hamann, S. D., \& Spinner, E. 1977, Aust. J. Chem., 30, 2591

Herrero, V. J., Gálvez, O., Maté, B., \& Escribano, R. 2010, Phys. Chem. Chem. Phys., 12, 3164

Johari, G. P., Hallbrucker, A., \& Mayer, E. 1987, Nature, 330, 552

Keane, J. V., Tielens, A. G. G. M., Boogert, A. C. A., Schutte, W. A., \& Whittet, D. C. B. 2001 , A\&A, 376, 354

Kessler, M. F. 2002, Adv. Space Sci., 30, 1957

Kouchi, A., \& Yamamoto, T. 1995, Prog. Crystal. Growth Charact., 30, 83

Knez, C., et al. 2005, ApJ, 635, L145

Lacy, J. H., Baas, F., Allamandola, L. J., Persson, S. E., McGregor, P. J., Lonsdale, C. J., Geballe, T. R., \& Vandebult, C. E. P. 1984, ApJ, 276, 533

Martín-Llorente, B., Frenández-Torre, D., Herrero, V. J., Ortega, I. K., Escribano, R., \& Maté, B. 2006, Chem. Phys. Lett., 427, 300

Marx, D., Tuckermann, M. E., Hütter, J., \& Parinello, M. 1999, Nature, 397, 601

Mastrapa, R. M., Shandford, S. A., Roush, T. L., Cruikshank, D. P., \& Ore, C. M. D. 2009, ApJ, 701, 1347

Maté, B., Gálvez, O., Herrero, V. J., Fernández-Torre, D., Moreno, M. A., \& Escribano, R. 2009, ApJ, 703, L178

Maté, B., Medialdea, A., Moreno, M. A., Escribano, R., \& Herrero, V. J. 2003, J. Phys. Chem. B, 107, 11098

Mayer, E. 1985, J. Appl. Phys., 58, 663

Moon, E.-S., Kang, H., Oba, Y., Watanabe, N., \& Kouchi, A. 2010, ApJ, 713, 906

Moore, M. H., Donn, B., Khanna, R., \& Ahearn, M. F. 1983, Icarus, 54, 388

Moore, M. H., Tanabe, T., \& Nuth, J. A. 1991, ApJ, 373, L31

Novozamsky, J. H., Schutte, W. A., \& Keane, J. V. 2001, A\&A, 379, 588

Oba, Y., Miyauchi, N., Hidaka, H., Chigai, T., Watanabe, N., \& Kouchi, A. 2009, ApJ, 701, 464

Palumbo, M. E., Pendelton, Y. J., \& Strazzulla, G. 2000, ApJ, 542, 890

Park, J.-Y., \& Woon, D. E. 2006, ApJ, 648, 1285

Pontoppidan, K. M., et al. 2003, A\&A, 408, 981

Raunier, S., Chiavassa, T., Marinelli, F., Alouche, A., \& Aycard, J. P. 2003, J. Phys. Chem. A, 107, 9335

Raunier, S., Chiavassa, T., Marinelli, F., \& Aycard, J. P. 2004, Chem. Phys., 302, 259

Raut, U., Famá, M., Teolis, B. D., \& Baragiola, R. A. 2007, J. Chem. Phys., 127,204713

Schutte, C. J. H., \& Buijs, K. 1964, Spectrochim. Acta, 20, 187

Schutte, W. A., \& Greenberg, J. M. 1997, A\&A, 317, L43

Schutte, W. A., \& Khanna, R. K. 2003, A\&A, 398, 1049

Schutte, W. A., et al. 1999, A\&A, 343, 966

Tielens, A. G. G. M., \& Hagen, W. 1982, A\&A, 114, 245

van Broekhuizen, F. A., Keane, J. V., \& Schutte, W. A. 2004, A\&A, 415, 425

Wagner, E. L., \& Hornig, D. F. 1950, J. Chem. Phys., 18, 296

Werner, M. W., et al. 2004, ApJS, 154, 1

Zasowski, G., Kemper, F., Watson, D. M., Furlan, E., Bohac, C. J., Hull, C., \& Green, J. C. 2009, ApJ, 694, 459

Zundel, G. 2000, Adv. Chem. Phys., 111, 1 